\section{Extended distribution of Smithsonia straminea C.J. Saldanha, an endemic orchid in Maharashtra, India}

\author{
Mandar N. Datar ${ }^{1} \&$ Vinaya S. Ghate ${ }^{2}$ \\ 1,2 Botany Group, Agharkar Research Institute, Pune, \\ Maharashtra 411004, India \\ Email: ${ }^{1}$ datarmandar@gmail.com (corresponding author), \\ 2vsghate@yahoo.com
}

During one of the routine floristic surveys of sacred groves of Dapoli Taluka, Ratnagiri District in the Konkan region of Maharashtra, a population of an interesting epiphytic orchid was observed near Kudavale sacred grove. After critical studies of the collected sample and review of literature (Pande et al. 2010; Rao \& Sridhar 2007) this orchid was identified as Smithsonia straminea C.J. Saldanha. Scrutiny of available floristic literature and works on orchids (Mistry 1986; Lakshminarasimhan 1996; Almeida 2009) also revealed that so far this taxon is known only from Karnataka and Kerala. Therefore, this is the first report of occurrence of the taxa in Maharashtra, indicating its extended distribution.

Saldanha (1976) described Smithsonia straminea based on collections from Hassan District, Karnataka. Joseph \& Vajravelu (1979) reported its extended distribution in Kerala. Kumar et al. (2000) added a few more locations in Kerala for its occurrence. The status of

Date of publication (online): 26 February 2012

Date of publication (print): 26 February 2012

ISSN 0974-7907 (online) | 0974-7893 (print)

Editor: Pankaj Kumar

Manuscript details:

Ms \# 02925

Received 25 August 2011

Final received 26 November 2011

Finally accepted 11 January 2012

Citation: Datar, M.N. \& V.S. Ghate (2012). Extended distribution of Smithsonia straminea C.J. Saldanha, an endemic orchid in Maharashtra, India. Journal of Threatened Taxa 4(2): 2406-2408.

Copyright: (c) Mandar N. Datar \& Vinaya S. Ghate 2012. Creative Commons Attribution 3.0 Unported License. JoTT allows unrestricted use of this article in any medium for non-profit purposes, reproduction and distribution by providing adequate credit to the authors and the source of publication.

Acknowledgements: The authors are thankful to the Director, Agharkar Research Institute, Pune for providing necessary facilities.

OPEN ACCESS I FREE DOWNLOAD (c) (i) (4) this Western Ghats endemic orchid has been evaluated as Endangered (EN) following the IUCN criteria 2000 (Kumar et al. 2000). As this paper reports its extended distribution to the north, this assessment needs to be re-evaluated. Since this is the first report of its occurrence in Maharashtra, a brief description of the species, ecological notes and field photographs (Image 1) are provided below to facilitate easy identification. The voucher specimens are deposited in Agharkar Herbarium (AHMA) of the Agharkar Research Institute, Pune.

Smithsonia straminea C.J. Saldanha, J. Bombay Nat. Hist. Soc. 71: 73. 1974; Saldanha in Saldanha \& Nicolson, Fl. Hassan Dist. 850. 1976. Loxoma straminea (Saldanha) U.C. Pradhan, Indian Orchids 2: 718.1979; Karthikeyan, et al. Florae Indicae Enumeratio Monocotyledonae 150. 1989. (Image 1).

Epiphytic herbs; Roots 3-6, arising from the base of the stem, up to $10 \mathrm{~cm}$ long. Stem very short. Leaves 2-4, distichous, coriaceous, elliptic-oblong and slightly channeled, bilobed or entire at apex. Racemes 1-2, shorter than the leaves, 4-18 flowered. Flowers sessile, about $0.5 \mathrm{~cm}$ across; sepals straw colored with red spots, obovate, $1.5 \times 3.0 \mathrm{~mm}$; petals slightly smaller and narrower, yellow with red spots, in some individuals red spots on sepals and petals totally absent; lip immovable, spurred, 3-lobed; spur pink, sub-conical or bacciform, 3-4 mm long; lateral lobes white, erect, acute; mid-lobe white, transverse, arching downwards, entire, with a small knob near the junction with the spur; anther cap yellowish; pollinia 2 , deeply cleft; stipe single, ending in viscidium. Rostellum 2-lobed. Capsule elliptic-obovate, ribbed, about $0.5 \times 1.5 \mathrm{~cm}$.

Locality and ecological observations: The species was recorded in a mango plantation near the Kudavale Sacred Grove in Kudavale Village along the Mandangad-Dapoli Road in Dapoli Taluka, Ratnagiri District of Maharashtra at $17^{0} 51^{\prime} 44.77^{\prime \prime} \mathrm{N}$ \& $73^{\circ} 14$ '40.48"'E, elevation of $840 \mathrm{~m}$. At Kudavale, the species was seen growing as epiphytes on lower branches of the trunks of Mangifera indica $\mathrm{L}$. 'Alphonso' with other epiphytic orchid associates like Vanda testacea (Lindl.) Rchb.f., Cottonia peduncularis (Lindl.) Rchb. $f$. and the fern Pyrrosia lanceolata (L.) Farw. The trees growing on the outskirts of 

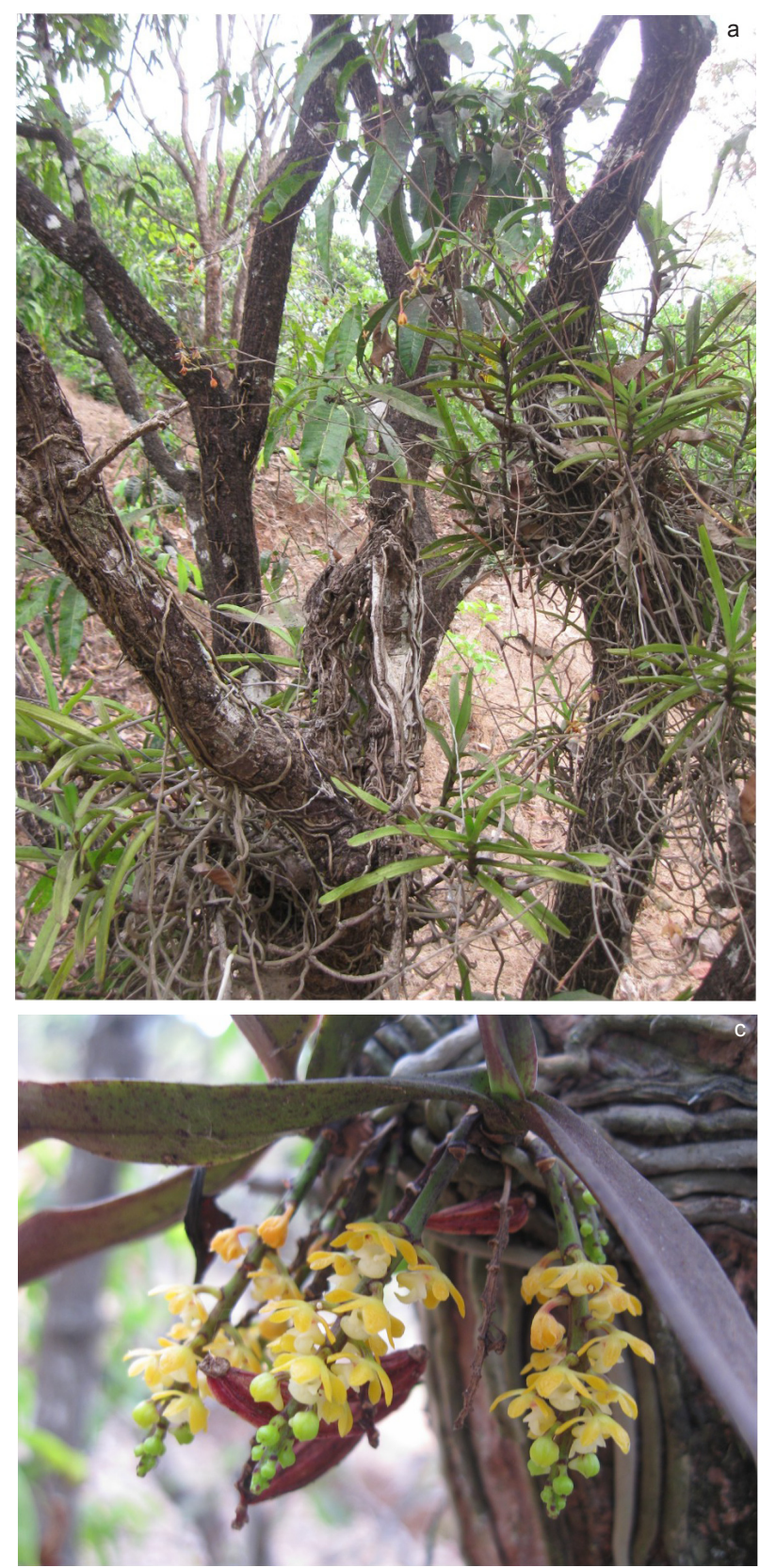

Image 1. Smithsonia straminea C.J. Saldanha a - Habitat of the orchid; $\mathbf{b}$ - habit; $\mathbf{c}$ - sepals and petals without red spot: variation; $d$ - flower close-up; e - pollinarium; $f$ - capsule

the mango orchard had predominant growths of orchids as compared to the trees inside the orchard. The maximum and luxuriant growth of these three species of orchids was noted on mango trees near the stream. Approximately 110 individuals of Smithsonia straminea were observed as epiphytic on 12 mango trees out of the total 60 trees growing in the orchard. The efforts to locate the species in nearby mango orchards, forest areas and sacred groves were without
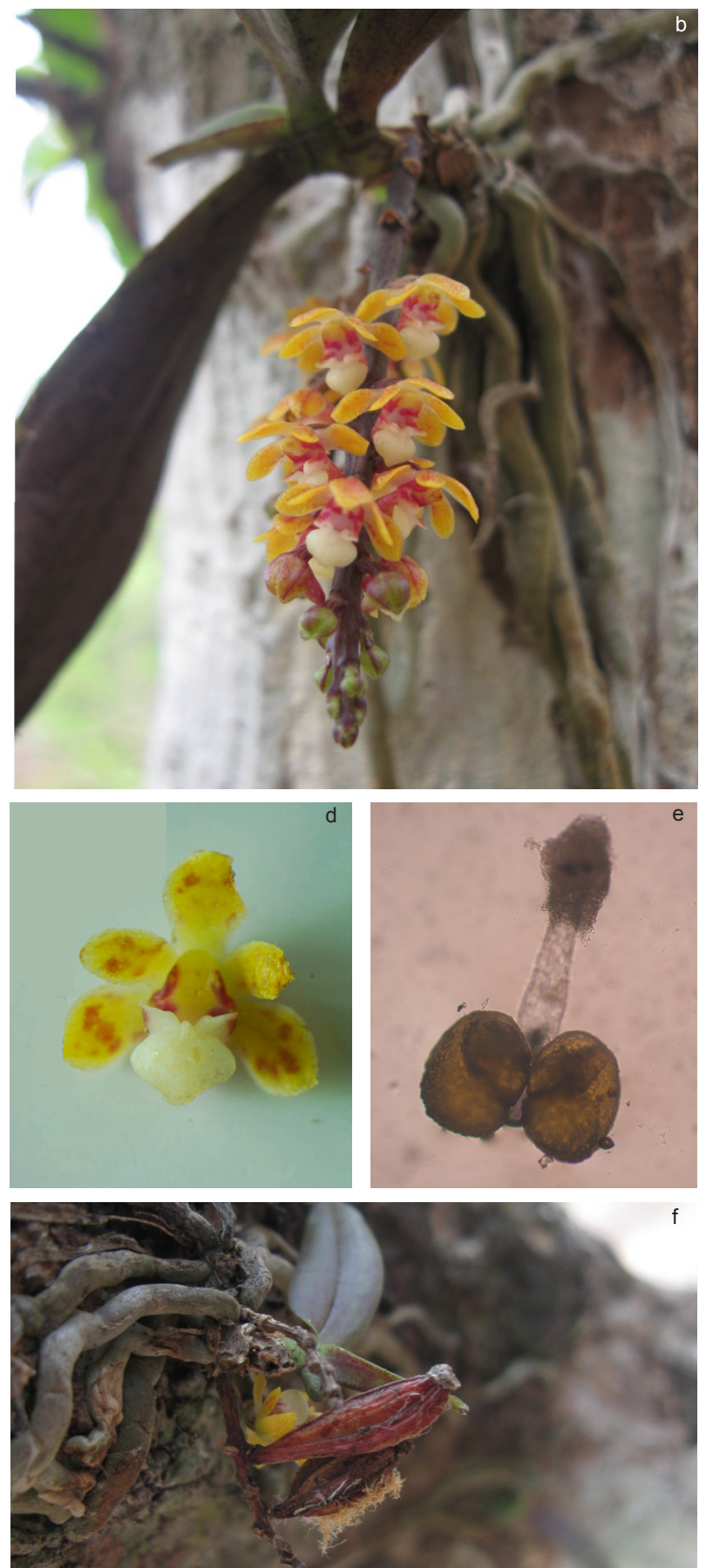

success. Pande et al. (2010) had earlier observed the species growing epiphytic on Terminalia alata Heyne ex Roth. in Belgaum District of Karnataka.

Flowering Phenology: May-June.

Exsiccata: Kudavale, 18.v.2011, Datar 25345 \& 25346 (AHMA) (Appendix $1 \& 2$ ). 


\section{REFERENCES}

Almeida, M.R. (2009). Flora of Maharashtra-Vol. Va. Blatter Herbarium, Mumbai, 245pp.

Joseph, V. \& E. Vajravelu (1979). First Report of Oberonia brachyphylla Blatt. \& McCann and Smithsonia straminea Saldanha (Orchidaceae) in Kerala. Bulletin of Botanical Survey of India 20(1-4): 169.

Kumar, C.S., B.V. Shetty, D. Bennet \& S. Molur (2000). Report of the Conservation Assessment and Management Plan Workshop on Endemic Orchids of the Western Ghats. Zoo Outreach, Organization \& CBSG South Asia, Coimbatore, India, 139pp.

Lakshminarasimhan, P. (1996). Orchidaceae, pp. 8-64. In: Sharma, B.D., S. Karthikeyan, \& N. P. Singh (eds.). Flora

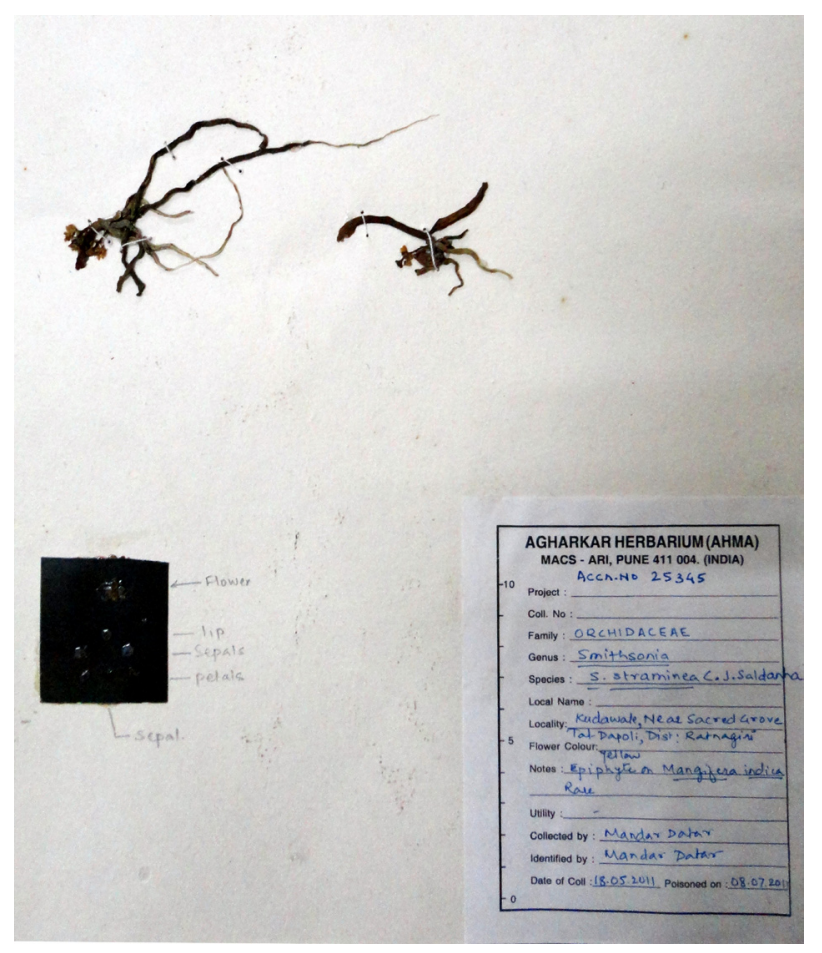

Appendix $1 \& 2$. Herbarium sheets of Maharashtra State, . Botanical Survey of India, Calcutta, 794pp.

Mistry, M.K. (1986). Flora of Ratnagiri District. PhD Thesis submitted to Mumbai University, India. (Unpublished).

Pande, S., N. Sant, V. Vishwasrao \& M.N. Datar (2010). Wild Orchids of Northern Western Ghats. Tata Power and Ela Foundation, India, 238pp.

Rao, T.A. \& S. Sridhar (2007). Wild Orchids in Karnataka, A Pictorial Compendium. Institute of Natural Resource conservation, Education, Research and Training, Bangalore, 103 pp.

Saldanha, C. J. (1976). Orchidaceae. In: Saldanha, C.J. \& H. Nicolson (eds). Flora of Hassan District, Karnataka, India. Amerind Pubication Co., New Delhi, 850pp.

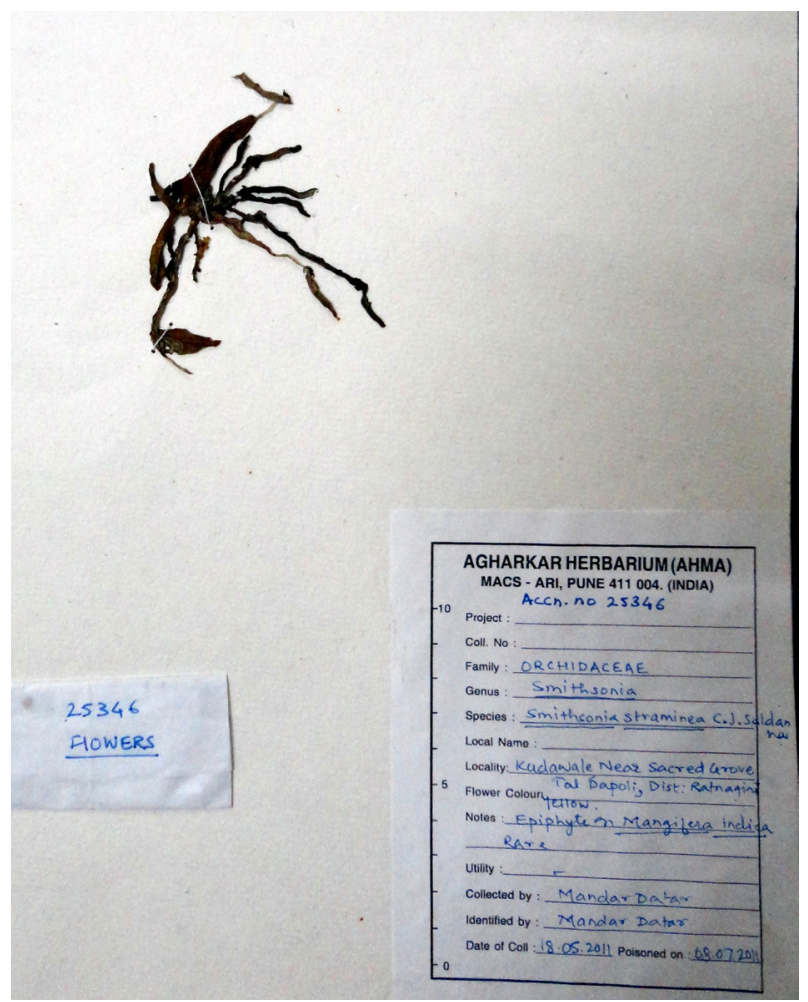

